\title{
Association Between Visceral Fat and Inflammatory Cytokines in Reflux Esophagitis
}

\author{
Sang Wook Kim \\ Department of Internal Medicine, Research Institute of Clinical Medicine, Chonbuk National University Medical School and Hospital, Jeonju, \\ Jeollabuk-do, Korea
}

Article: The Effect of abdominal visceral fat, circulating inflammatory cytokines, and leptin levels on reflux esophagitis Nam SY, Choi IJ, Ryu KH, et al

(J Neurogastroenterol Motil 2015;21:247-254)

The results of several previous studies have suggested that abdominal obesity is an important risk factor for reflux esophagitis. ${ }^{1,2}$ Among factors related to obesity, visceral fat is more associated with erosive esophagitis than body mass index (BMI). ${ }^{3}$ Physiologic abnormalities related to prolonged esophageal acid exposure have been found to occur more frequently in obese individuals than in those with normal weight. Obese subjects revealed abnormal esophageal manometric findings such as nonspecific motility disorder, nutcracker esophagus, and hypotensive lower esophageal sphincter as the most common manometric results. ${ }^{4}$ Transient relaxations of the lower esophageal sphincter (TRLES) is also reported to be more common in patients with obesity. The main stimulus for TRLES is gastric distension especially in the gastric fundus. ${ }^{5}$ Pandofino et $\mathrm{al}^{6}$ reported esophageal manometric findings suggesting that the pressure morphology within and across the esophagogastric junction were altered in obesity, which could augment the flow of gastric juices into the esophageal lumen. This anatomical disruption of the esophagogastric junction results in further hiatal hernia formation.

Esophageal mucosal injury is associated with increased exposure to gastric acid. However, maintenance of chronic esophageal mucosal inflammation and esophageal metaplasia such as Barrett's esophagus (BE) or esophageal carcinoma in obese subjects have been proposed to increase inflammatory cytokines from visceral adipose tissue. ${ }^{7}$ The relationship between obesity and esophageal neoplasia may be due to alterations in the secretion of adipokines such as adiponection and leptin. Adiponection has an anti-inflammatory effect and stimulates apoptosis, which shows inverse relationship between obesity and adiponection. ${ }^{8}$ Leptin, a satiety hormone, is secreted by adipocytes and gastric chief cells. Esophageal epithelial cells express leptin receptors. In an esophageal adenocarcinoma cell line, leptin has been shown to stimulate cell proliferation and inhibit apoptosis via cyclooxygenase- 2 acti-

Received: February 21, 2015 Revised: March 18, 2015 Accepted: March 24, 2015

(c) This is an Open Access article distributed under the terms of the Creative Commons Attribution Non-Commercial License (http://creativecommons. org/licenses/by-nc/3.0) which permits unrestricted non-commercial use, distribution, and reproduction in any medium, provided the original work is properly cited.

*Correspondence: Sang Wook Kim, MD

Department of Internal Medicine, Research Institute of Clinical Medicine, Chonbuk National University Medical School and Hospital, 20, Geonji-ro, Deokjin-gu, Jeonju, Jeollabuk-do, 561-712, Korea

Financial support: None. Tel: +82-63-250-2302, Fax: +82-63-254-1609, E-mail: clickm@jbnu.ac.kr

Conflicts of interest: None.

ORCID: http://orcid.org/0000-0001-8209-540X. 
vation of the epidermal growth factor receptor. ${ }^{9}$ Several studies have suggested a positive association between plasma leptin and BE. ${ }^{10,11}$ Kendall et al ${ }^{12}$ reported that a high serum leptin level is associated with an increased risk of $\mathrm{BE}$ among men, but not women.

No previous reports have documented the relationship between circulating cytokines and reflux esophagitis (RE). Recently, Nam ${ }^{13}$ conducted an interesting case-control study that suggested circulating cytokines were correlated with the risk of erosive esophagitis. They used abdominal visceral fat instead of $\mathrm{BMI}$ and plasma leptin level had a positive correlation with RE. The visceral fat/total fat ratio was used as an obesity index because there is no standard cut off value for defining obesity. The results indicated that both visceral fat and the visceral fat/total fat ratio were positively correlated with IL-6, IL-8, and IL-1 $\beta$, but were negatively associated with adiponectin. Leptin showed no association with visceral fat, but had a strong association with the visceral fat/total fat ratio. Only visceral fat/100 and leptin were positively correlated with RE after adjusted analysis for both inflammatory cytokines and obesity indexes.

Despite the positive correlation of visceral fat and leptin with risk of RE, they did not classified reflux symptom strength or severity of esophagitis. Moreover, cytokine has its effect through ligand mediate reaction. Elevated plasma levels of cytokines do not always reflect cytokine bioactivity in inflamed regions. Checking the receptor expression and cytokine levels in target tissue provides more information about cytokine-ligand mediated responses. ${ }^{14,15}$

In conclusion, obesity is an important risk factor for developing gastroesophageal reflux disease. Abdominal visceral fat is a more useful obesity index for RE than BMI. To clarify the role of circulating cytokines in obese subjects with RE, further studies with large populations are needed, which will also help elucidate the pathophysiology between obesity and RE.

\section{References}

1. Lee HL, Eun CS, Lee OY, et al. Association between GERD-related erosive esophagitis and obesity. J Clin Gastroenterol 2008;42: 672-675.
2. Hampel H, Abraham NS, EL-Serag HB. Meta-analysis: obesity and the risk for gastroeneophageal reflux disease and its complications. Ann Intern Med 2005;143:199-211.

3. Nam SY, Choi IJ, Ryu KH, Park BJ, Kim HB, Nam BH. Abdominal visceral adipose tissue volume is associated with increased risk of erosive esophagitis in men and women. Gastroenterology 2010;139:1902-1911, e2.

4. Koppman JS, Poggi L, Szomstein S, Ukleja A, Botoman A, Rosenthal R. Esophageal motility disorders in the morbidly obese population. Surg Endosc 2007;21:761-764.

5. Kahrilas PJ, Shi G, Manka M, Joehl RJ. Increased frequency of transient lower esophageal sphincter relaxation induced by gastric distention in reflux patients with hiatal hernia. Gastroenterology 2000;118:688-695.

6. Pandolfino JE, El-Serag HB, Zhang Q, Shah N, Ghosh SK, Kahrilas PJ. Obesity: a challenge to esophagogastric junction integrity. Gastroenterology 2006;130:639-649.

7. Coussens LM, Werb Z. Inflammation and cancer. Nature 2002; 420:860-867.

8. Kelesidis I, Kelesidis T, Mantzoros CS. Adiponectin and cancer: a systematic review. Br J Cancer 2006;94:1221-1225.

9. Oqunwobi O, Mutungi G, Beales IL. Leptin stimulates proliferation and inhibits apoptosis in Barrett's esophageal adenocarcinoma cells by cyclooxygenase-2-dependent, prostaglandin-E2mediated transactivation of the epidermal growth factor receptor and c-Jun $\mathrm{NH}_{2}$-terminal kinase activation. Endocrinology 2006;147: 4505-4516.

10. Rubenstein JH, Morgenstern H, Mc Conell D, et al. Associations of diabetes mellitus, insulin, leptin, and ghrelin with gastroesophageal reflux and Barrett's esophagus. Gastroenterology 2013;145:12371244, e1-e5.

11. Mokrowiecka A, Daniel P, Jasinska A, et al. Serum adiponectin, resistin, leptin concentration and central adiposity parameters in Barrett's esophagus patients with and without intestinal metaplasia in comparison to healthy controls and patients with GERD. Hepatogastroenterology 2012;59:2395-2399.

12. Kendall BJ, Macdonald GA, Hayward NK, et al. Leptin and the risk of Barrett's esophagus. Gut 2008;57:448-454.

13. Nam SY, Choi IJ, Ryu KH, et al. The effect of abdominal visceral fat, circulating inflammatory cytokines, and leptin levels on reflux esophagitis. J Neurogastroenterol Motil 2015;21:247-254.

14. Souza RF, Huo X, Mittal V, et al. Gastroesophageal reflux might cause esophagitis through a cytokine-mediated mechanism rather than caustic acid injury. Gastroenterology 2009;137:1776-1784.

15. Rieder F, Cheng L, Hamett KM, et al. Gastroesophageal reflux diseas-associated esophagitis induces endogenous cytokine production leading to motor abnormalities. Gastroenterology 2007;132:154-165. 